\title{
Inter-aviary distance and visual access influence conservation breeding outcomes in a territorial, endangered bird
}

\author{
Alison M. Flanagan ${ }^{1 *}$, Christian Rutz ${ }^{2,3}$, Susan Farabaugh ${ }^{1}$, Alison L. Greggor ${ }^{1}$, Bryce Masuda ${ }^{1}$, \\ Ronald R. Swaisgood ${ }^{1}$ \\ ${ }^{1}$ Institute for Conservation Research, San Diego Zoo Global, Escondido, CA 92027, USA \\ ${ }^{2}$ Centre for Biological Diversity, School of Biology, University of St Andrews, Sir Harold \\ Mitchell Building, St Andrews KY16 9TH, UK \\ ${ }^{3}$ Present address: Radcliffe Institute for Advanced Study, Harvard University, Cambridge, MA \\ 02138, USA
}

Acknowledgements: We would like to thank the many partners, collaborators, supporters, and funders of the HEBCP, including numerous nonprofits, land holders, universities, businesses, communities, and state and federal agencies. We sincerely thank Richard James for his help with developing a coding system for the 'Alalā housing database. Funding for setting up the housing database was provided by the UK's Biotechnology and Biological Sciences Research Council (BBSRC; grant BB/G023913/2 to C.R.). Conservation breeding efforts are conducted under U.S. Fish and Wildlife Service permit TE060179-6, State of Hawaii Department of Land and Natural Resources permit WL19-16, and San Diego Zoo Global IACUC 16-009.

* Corresponding author: Alison M. Flanagan, Hawai'i Endangered Bird Conservation Program, Institute Conservation Research, San Diego Zoo Global, P.O. Box 39, Volcano, HI 96785; phone: 631-790-8393; alflanagan@sandiegozoo.org 


\title{
Inter-aviary distance and visual access influence conservation breeding outcomes in a territorial, endangered bird
}

\section{Keywords}

Animal husbandry; conservation breeding; endangered birds; social density; enclosure design; Hawaiian crow

\section{Highlights}

- Reproductive success can be adversely impacted by high social density

- The design and spatial configuration of enclosures impacts reproductive success

- Blocking visual access to conspecifics improves reproductive success

- Enclosure designs that minimize stress can help to improve reproductive success

\begin{abstract}
Species extinctions are becoming a global crisis, affecting biodiversity and ecosystem services, with island populations being particularly vulnerable. In response, conservation managers are increasingly turning to ex situ conservation breeding programs to establish assurance populations and provide a source for release and re-establishment of wild populations. The 'Alalā (Hawaiian crow, Corvus hawaiiensis) is a critically endangered and territorial island corvid that became extinct in the wild in 2002, following a severe and prolonged population decline during the late $20^{\text {th }}$ century. Surviving individuals of the species were brought into captivity to establish an assurance population to serve as a source for reintroduction, which commenced in 2016 . We analyzed the extent to which a range of captive housing conditions impact 'Alalā reproductive success, using 19 years of breeding program data. We found that reproductive success was most strongly affected by the distance between aviaries and their closest neighbors and whether breeding pairs had visual access to other adult conspecifics. Pairs located in aviaries that were more spatially isolated and without visual access to conspecifics were more likely to produce fertile eggs than pairs housed in aviaries that were closer to others or those with visual access to other birds. Our results have direct management implications relevant to the design of conservation breeding centers geared towards the recovery of endangered, territorial bird species. Moreover, since suboptimal housing conditions can increase stress levels in captive birds, our findings are also relevant to improving animal welfare for 'Alalā and other species in conservation breeding programs.
\end{abstract}

\section{Introduction}

At a time when species extinctions are becoming commonplace (Barnosky et al., 2011), conservationists and field biologists are beginning to quantify what is being lost. Species make incalculable contributions to ecosystem function, ecosystem services, and other values important to humanity (Gascon et al., 2015; Hooper et al., 2012; Richardson and Loomis, 2009). As preventing extinctions in nature becomes more intractable in many cases, conservation practitioners have turned increasingly to conservation breeding (i.e., captive propagation; Conde et al., 2011). In fact, the IUCN and U.S. Fish \& Wildlife Service have identified over 1,000 vertebrate taxa in need of conservation breeding for recovery (reviewed in Bowkett, 2009). However, the urgency with which many conservation breeding programs are establishedcoupled with their limited resources, small sample sizes, and constraints on controlled experimentation - means that breeding efforts typically get underway before research can be conducted to develop optimal strategies. This need to take action in the face of uncertainty lends 
itself to the adaptive management approach where decisions are being made initially based on incomplete information but subsequently adjusted in light of lessons learned during implementation (Canessa et al., 2016). However, there are many cases in which adaptive management principles were not applied at the onset of the program, and, in the case of some legacy data, record-keeping may pre-date the widespread use of adaptive management and planning. In cases such as these it may be possible to glean lessons from past management choices where data are available for evaluating important outcomes following those choices. While conclusions from such a retrospective analysis may be more tentative than those from a well-designed adaptive management experiment, they can still provide important insights to guide future management decisions. For example, in a giant panda conservation breeding program, historical records enabled an assessment of the relative efficacy of natural mating versus artificial insemination, even though the methods had never been compared in a planned experiment (Li et al., 2017).

Fundamental to conservation breeding outcomes is the design and layout of enclosures. Managers must decide how large to make enclosures, what sorts of habitat and enrichment to provide, how many animals to place in an enclosure, how to select enclosure mates for social compatibility, and how to arrange multiple enclosures in space (Carlstead, 1996; Morgan and Tromborg, 2007). In particular, the social environment is known to influence reproduction across several species. In fact, the Allee effect postulates the existence of an optimal population density - or more appropriately, an optimal degree of social contact and communication opportunities - that promotes reproduction (Stephens and Sutherland, 1999). Too few individuals and normal courtship and mating cannot take place but, if overcrowding occurs, stress and resource competition can negatively impact reproduction. While the optimal population density may differ between species, the basic principles are expected to apply broadly across many taxonomic groups and situations. In captive environments, most research to date has focused on the effects of same-enclosure social environment on captive reproduction (Lindburg and FitchSnyder, 1994; Swaisgood and Schulte, 2010). A counter-example illustrates the value of considering the broader social environment outside the enclosure. In the mongoose lemur (Eulemur mongoz), housing monogamous pairs in the vicinity of other conspecific pairs had a facilitatory effect on reproduction, leading to large increases in offspring production (Hearn et al., 1996). More commonly, negative effects of the captive social environment have been considered, which can be mediated by stress (Morgan and Tromborg, 2007). High social density is a known stressor and can negatively influence reproduction in both wild (Creel et al., 2013) and captive populations (Morgan and Tromborg, 2007). In a controlled experiment with European starlings (Sturnus vulgaris), simply moving birds from a large outside aviary to a smaller indoor aviary (increasing social density by reducing available space) led to cessation of reproductive activity (Dickens and Bentley, 2014).

Here, we analyze a long-term dataset to determine how inter-aviary distance and visual access to neighbors influences reproduction in one of the world's most endangered bird species, the 'Alalā or Hawaiian crow (Corvus hawaiiensis). Throughout the Hawaiian archipelago, forest bird populations have dramatically declined largely due to anthropogenic habitat loss and degradation, introduced mammalian predators, and foreign disease (avian smallpox and avian malaria; Reed et al., 2012). Nearly 100 native forest bird species in Hawai'i became extinct after the arrival of humans; today, only 21 species remain, 12 of which are listed as endangered (Paxton et al., 2018). The 'Alalā-perhaps the most iconic representative of this crisis — is the 
last corvid remaining on the Hawaiian Islands, which historically was home to at least 5 crow species (James and Olson, 1991). The "Alalā, nearly extinct, thus occupied an ecological niche that has gone unfilled in modern times (Culliney et al., 2012).

In response to dramatic declines, an assurance population for 'Alalā and other endemic endangered species was established in the Hawai'i Endangered Bird Conservation Program (HEBCP). Although many of the introduced threats to Hawaiian avifauna are intractable, it is possible to restore and maintain suitable habitat that can serve as refuges where species can continue to exist in the wild (Reed et al., 2012; Paxton et al. 2018). Through conservation breeding, reintroduction, and intensive management intervention to control threats, some species such as the Nēnē or Hawaiian goose (Branta sandvicensis) have begun to recover (Reed et al., 2012). Conservation breeding is considered one of the top priorities for rescuing Hawaiian avifauna from extinction (Paxton et al. 2018). 'Alalā went extinct in the wild in 2002 and, until recent release efforts began in 2016, this species only survived in captivity. As of August 2019, there are a total of 138 'Alalā, including 119 captive birds and 19 individuals in the wild, the largest number of 'Alalā in nature in over two decades (Banko et al., 2002). Since launching intensive conservation breeding efforts with 'Alalā in 1996, the HEBCP has maintained detailed records for every egg laid along with thorough reports on management strategies, providing an excellent opportunity to evaluate retrospectively how program management can be used to improve reproductive success in this critically endangered island corvid.

The 'Alalā's social system can be characterized as group territorial, with breeding pairs defending mutually exclusive territories (Banko et al., 2002). Records from the 1990s suggest they occupied large territories, separated by a kilometer per breeding pair (Banko, 2009), although they may have occurred in higher densities before their severe population decline (Perkins, 1903). Although often with dependent young, pairs did not have extended contact with other adult 'Alalā during the breeding season, and contact at that time was frequently aggressive in nature. Thus, we predicted that breeding pairs located in aviaries near adult conspecifics and/or those that had visual access to other adults, would be less likely to reproduce than pairs located in aviaries that are more spatially isolated (e.g., $\sim 25$ to $50 \mathrm{~m}$ away from other aviaries), or do not have visual access to conspecifics. Commensurate with the increasing role for captive breeding in conservation, our study provides timely insights that can be used to inform the design and management of conservation breeding centers for captive propagation of Hawaiian and other avifauna.

\section{Methods}

The HEBCP has two breeding centers, the Keauhou Bird Conservation Center (KBCC) on the island of Hawai' $i$ and the Maui Bird Conservation Center (MBCC) on Maui. 'Alalā aviaries are located outdoors, have covered areas for shelter and feeding, and consist of two to six compartments, all of which were separated by wire mesh walls until 2017 when the HEBCP began installing visual barriers in aviaries with more than two compartments. While the aviaries vary in size (buildings measure $\sim 74$ to $149 \mathrm{~m}^{2}$; individual compartments are $\sim 22$ to $37 \mathrm{~m}^{2}$ ), all were designed in an attempt to provide sufficient space to allow 'Alalā to engage in speciestypical behaviors such as roosting, foraging, flying, and bathing, and to minimize contact with animal husbandry staff (Greggor et al., 2018). At present, distances between each aviary and its closest neighbor range between $\sim 4$ and $100 \mathrm{~m}$. The current minimum distance between the aviaries at $\mathrm{KBCC}$ is $\sim 30 \mathrm{~m}$, and the maximum distance between the aviaries at $\mathrm{MBCC}$ is $\sim 50 \mathrm{~m}$ 
(see the Supplementary Material for a more in-depth description of the aviary layouts at both breeding centers).

The 'Alalā breeding season begins in March and ends in late-July or early-August. 'Alalā breeding pairs have been selected based on genetic assessments (primarily mean kinship), age structure, individual and pair-specific breeding history and behavior, and anecdotal assessments of pair compatibility by husbandry staff. In 2019, the HEBCP transitioned to the use of mate choice assessments to improve pair selection and compatibility (Greggor et al., 2018). 'Alalā are social as juveniles but become territorial as adults at about 2 to 3 years of age as they reach sexual maturity (Banko et al., 2002). During each breeding season, breeding pairs were housed in aviaries with two compartments to provide opportunities for pairs to regulate social proximity and to allow husbandry staff to separate pair partners when necessary. However, due to the success of the breeding program and the resultant growth of the captive flock, this has not always been possible despite the construction of new aviaries to provide additional space.

Our study utilized a long-term dataset that combined an extensive breeding record database from Hoeck et al. (2015) and housing information from Rutz et al. (2016). We updated these datasets to include recent breeding seasons through 2018. HEBCP breeding records and housing information from 1996 to 1999 were sparse, so we restricted our analyses to the 2000 through 2018 breeding seasons. While we conducted extensive quality checks of our full dataset prior to analyses (complementing earlier checks carried out by Hoeck et al. (2015) and Rutz et al. (2016)), there are still some gaps in the data, particularly with regards to the housing locations of some birds; however, it is highly unlikely that the housing location gaps would systematically affect the relationships explored in our study. Wherever possible, housing location gaps were filled by inferring the locations of birds within a particular breeding season based on their known location (aviary) in preceding/following breeding seasons or the known location of their mate. It is important to note that breeding pairs were housed in the same aviary for 1 to 8 years with some pairs contributing multiple observations to the same aviary and associated distance class, although construction of new aviaries nearby sometimes altered inter-aviary distance for pairs held in existing aviaries. However, $87.0 \%$ of the individuals included in our analyses were housed in the same aviary with the same mate for just 1 to 3 years and only two pairs were housed in the same aviary for 8 consecutive years. It is therefore unlikely that housing management decisions, albeit nonrandom, had an undue influence on the outcome of our retrospective analyses (but see the Supplementary Material for quantitative results supporting this assumption).

The full dataset included a total of 156 breeding pairs across 19 breeding seasons. Breeding pairs were defined as any male-female pair that was housed in the same aviary with physical access to one another during the breeding season and therefore had the opportunity to mate. The number of pairs per breeding season increased over time and ranged from 9 to 47 in more recent breeding seasons. We restricted our analyses to individuals that were with the same mate throughout each breeding season $(n=141)$ and defined reproductive success as whether or not a breeding pair produced $\geq 1$ confirmed fertile egg. Fertility was confirmed by egg candling. Eggs without visible signs of development either died during the very early embryo stage or were infertile; however, eggs were rarely broken open to confirm infertility. We therefore decided to model whether or not pairs produced a fertile egg (lower uncertainty in the data) rather than the proportion of fertile eggs out of all eggs laid per breeding pair per year (higher 
uncertainty) as our metric of reproductive success. Since most eggs were pulled for artificial incubation, dummy eggs were often placed under nesting females to discourage them from laying an excessive number of clutches; thus, we were also unable to model the effects of housing conditions on the total number of fertile eggs produced by each pair. In addition, because most eggs were artificially incubated, we could not evaluate housing effects on hatchability.

To capture all potentially relevant housing effects on reproductive success, we developed a hierarchical captive housing characterization scheme that could be applied to all 'Alalā aviaries across the two breeding centers. From this perspective, each level of the scheme represents a variable that might impact whether breeding pairs engage in breeding behaviors (nest building, copulation, etc.) and ultimately produce a fertile egg. The larger scale variables included location (KBCC or $\mathrm{MBCC}$ ), distance in meters between each aviary and its closest neighbor (i.e., minimum inter-aviary distances measured from building edges in Google Earth), and distance classes $(\leq 25 \mathrm{~m},>25$ to $50 \mathrm{~m},>50 \mathrm{~m}$ to $75 \mathrm{~m}$, and $>75 \mathrm{~m})$ that were defined a priori and used to visualize how the spatial configuration of aviaries across the two breeding centers influences reproductive success. Since new aviaries were periodically constructed at KBCC and MBCC, causing inter-aviary distances to change over time, inter-aviary distances were determined on a year-to-year basis. We included the total number of 'Alalā within 10, 25, 50 and $75 \mathrm{~m}$ as a measure of social density across different spatial scales. Since HEBCP staff have long noticed that adult 'Alalā are unaffected by birds $\leq 2$ years of age, likely because subadults (i.e., nestlings, fledglings, and juveniles) represent a negligible threat to breeding pairs, we removed birds $\leq 2$ years of age prior to calculating social density (but see the Supplementary Material for model results that utilized the full dataset, including subadults). Smaller-scale variables included the total number of adult conspecifics housed in each aviary, whether breeding pairs had visual access to adult conspecifics in adjacent compartments within their aviary, whether breeding pairs were housed in the same aviary, but in different compartments from other adult birds, and, if so, whether breeding pairs were located next to a single male, a single female, or multiple birds.

We conducted all statistical analyses in R (R Core Team, 2017). Model-averaged generalized linear mixed-effects models (GLMMs) were used to test the impact of the captive housing conditions, derived from our housing characterization scheme, on the reproductive success of 'Alalā. Reproductive success (whether or not a breeding pair produced a fertile egg) was coded as binary and used as the response variable in our analyses. GLMMs were run using a binomial error distribution and logit link function, fit by maximum likelihood (Laplace approximation), and were carried out using the glmer command from the lme4 package (Christensen, 2018).

Our global GLMM included the identities of the male and female comprising each breeding pair and year as random effects. The identities of the male and female were included as separate random effects to account for the fact that individuals contributed multiple observations with the same or different mates across breeding seasons. Year was included as a random effect since management practices, although standardized across the two breeding centers, varied from year-to-year. All possible predictors from our housing characterization scheme were included as numeric fixed effects in our initial global GLMM. Categorical variables, such as whether birds had visual access to their neighbors and location (KBCC or MBCC), were dummy coded so that they could be included as standardized numeric fixed effects in our global GLMM. 
We used Pearson correlation coefficients to identify and exclude highly correlated fixed effects prior to analysis and, in all but one case, dropped correlated fixed effects with coefficients $\geq 0.60$ (Table S2). Location and inter-aviary distance were correlated at 0.79 , but both were essential to include as predictors of reproductive success; thus, we retained them in our global GLMM and subsequently evaluated multicollinearity within the GLMM using variance inflation factors (VIF) to ensure that the covariates used in model averaging had VIF $<5$ (e.g., Belsley et al., 1980; Weiser et al. 2015). VIFs were calculated using the vif command from the car package (Fox \& Weisberg, 2011). After excluding biologically relevant but correlated fixed effects, our final GLMM used in model averaging included location (KBCC or MBCC), inter-aviary distance, social density within $10 \mathrm{~m}$, visual access, whether pairs shared their aviary with other adult birds (housed in adjoining or non-adjoining compartments) and, if so, whether their neighbor was a single male or a single female. Visual access was selected over other relevant but correlated fixed effects (Table S2) since its importance had been hypothesized a priori for biological reasons and based on HEBCP staff's informal observations that breeding pairs with visual access to adult birds may exhibit compromised breeding behavior. The a priori distance classes were excluded from the analyses since they were derived from, and thus highly correlated with, inter-aviary distance; however, we used the distance classes to illustrate the extent to which inter-aviary distance and visual access impact reproductive success.

All numeric effects were standardized to a mean of 0 and standard deviation of 0.5 using the rescale function in the arm package (Gelman \& $\mathrm{Su}, 2018$ ). The dredge function in the MuMIn package was used to generate GLMM submodels (Barton, 2018) from the global GLMM. The best submodels, i.e., those within $\triangle \mathrm{AIC}_{\mathrm{C}} \leq 2$ of model with the lowest $\mathrm{AIC}_{\mathrm{C}}$ score (Grueber et al., 2011), were used in model averaging. Model averaging was implemented using the natural average method to obtain parameter estimates and relative importance (RI) scores for each fixed effect.

\section{Results}

Social density within a given year was similar across the distance classes at each breeding center (Figure 1). At KBCC, from 2000 to 2018, social density ranged from 1 to 9 adult birds within $10 \mathrm{~m}$ to as many as 21 birds within $75 \mathrm{~m}$. Social density at MBCC was higher, with as many as 29 birds within $10 \mathrm{~m}$ and up to 32 birds within $50 \mathrm{~m}$. The construction of additional aviaries at KBCC over the years minimized social density despite the growing captive flock since most of the newer aviaries were constructed $\sim 50 \mathrm{~m}$ or more away from one another (Figure 1). At MBCC, the addition of four aviaries, all within $\sim 10 \mathrm{~m}$ of one another and each with six compartments, increased social density at MBCC from 2011 onward (Figure 1). Of the 156 breeding pairs in the full dataset, $64(41.0 \%)$ produced at least one fertile egg during their lifetime as a pair.

Six submodels with the lowest AIC $_{C}$ scores were used in model averaging (Table S3). Of the housing effects included in our final model, inter-aviary distance and whether breeding pairs had visual access to adult conspecifics were the most important predictors of 'Alalā reproductive success $(\mathrm{RI}=1.00$ and 0.73 , respectively; Table 1$)$. All other fixed effects had low RI scores (Table 1). VIF was $<5$ for all fixed effects included in the model-averaged GLMM (Table 1). Pairs located in aviaries that were further away from others were more likely to produce fertile eggs than those housed in aviaries that were closer together. For instance, breeding pairs in aviaries located $\geq 50 \mathrm{~m}$ from neighboring aviaries were, on average, $57.0 \%$ more likely to 
produce a fertile egg than those located $\leq 50 \mathrm{~m}$ from other aviaries (Figure 2). For the a priori distance classes that included breeding pairs with and without visual access to other birds, the proportion of pairs that produced fertile eggs without visual access was almost always higher than pairs that could see neighboring conspecifics (Figure 3). In these cases, the proportion of breeding pairs without visual access that produced fertile eggs was $62.2 \%$ higher, on average, than those with visual access to conspecifics. Applying the same model-averaged GLMM to a dataset that was restricted to breeding pairs that resided in the same aviary for 1 to 3 consecutive years produced similar results (Tables S4 \& S5). Additionally, a model-averaged GLMM utilizing the dataset that included subadults (birds $\leq 2$ years of age) also yielded a similar outcome with inter-aviary distance and visual access (to adults or subadults) being the most important predictors of reproductive success (both with $\mathrm{RI}=1.00$; Table S6); although, only three submodels were selected based on the $\Delta \mathrm{AIC}_{\mathrm{C}} \leq 2$ and used in model averaging (Table S7).

\section{Discussion}

Our analyses of two decades of 'Alalā conservation breeding records indicate that housing arrangements that increase the potential for social interaction between breeding pairs and other adult conspecifics can have negative consequences for reproduction. Breeding pairs in aviaries with suboptimal housing conditions, such as those located closer to other 'Alalā aviaries and those that had visual access to adult conspecifics, were far less likely to produce fertile eggs than breeding pairs housed in aviaries that were more spatially isolated without visual access to other adults. The importance of distance between aviaries suggests that, going forward, the HEBCP and other conservation breeding centers geared towards the recovery of endangered, territorial avifauna should endeavor to build aviaries that consider needs for species-appropriate spatial separation. For 'Alalā that distance seems to be at least $\sim 25$ to $50 \mathrm{~m}$ away from neighboring aviaries. However, since the maximum distance between the HEBCP aviaries was $\sim 100 \mathrm{~m}$, it is unclear whether 'Alalā reproductive success would continue to improve if aviaries were $>100 \mathrm{~m}$ away from one another. An important caveat is that complete isolation from other conspecifics is not warranted (and not examined in our study). In fact, some degree of social interaction between individuals residing in different enclosures may be important for social learning and cultural transmission of key survival skills (see Brakes et al., 2019), such as specialized foraging techniques (Culliney et al., 2012; Rutz et al., 2016; Klump et al., 2018) or particular vocalizations (Tanimoto et al., 2017). More research is required for individual species bred in captivity to determine the optimal degree of social separation, which is likely to vary with size, mobility, primary communication modalities, and social system.

We acknowledge that space may be a limiting factor in many conservation breeding programs, but our study also indicates that provision of visual barriers can mitigate the effects of crowding, and this can provide a relatively inexpensive partial solution when there are spatial constraints. Since visual barriers seem to be effective for partially mitigating the effects of social density on a bird species with large territories, it may prove effective for a wide range of species, especially if they have smaller territories. Also, given that 'Alalā are a highly vocal species, that defend their territories through vocal broadcasts as deterrents (Tanimoto et al., 2017), it is notable that reductions in visual access improve reproductive outcomes even when some degree of acoustic access is maintained. Since our aviaries are open-air, the barriers we installed did not preclude acoustic access between pairs, but no doubt reduced the pressure levels of vocalizations perceived by neighboring pairs, and thereby may have given the impression that neighbors were further away. Thus, our barrier effect may have resulted from elimination of visual contact 
and/or reduction in acoustic contact. The influence on health, stress, and reproduction of varying degrees of conspecific communication, via different sensory modalities, in conservation breeding facilities is an area rich for future investigation. For example, future studies could manipulate access to conspecific communication signals and help determine how animals may be held under conditions of far greater social density while minimizing negative consequences. One experiment indicated by our research is to manipulate visual and acoustic contact independently through provision of barriers with and without visual access and sound-proofing (acknowledging that sound will carry above the walls for our outdoor facilities); a sound meter could be used to measure the pressure levels of vocalizations reaching subjects.

Suboptimal housing conditions have been linked to higher levels of stress in a variety of taxa (Morgan and Tromborg, 2007), and social stress is a likely mechanism explaining the reduction in reproductive success observed in our dataset. A number of studies, primarily with mammals but also with birds and other taxa, have established a role for HPA activation in density-dependent population regulation; as population size increases, glucocorticoid excretion increases and survival and reproduction decrease (e.g., Creel et al., 2013). These crowding effects often appear to be mediated by aggressive interactions with neighboring conspecifics in territorial species. In several bird species, for example, simulated territorial intrusions have been shown to increase HPA activity (Creel et al., 2013). The effects of social density on reproduction can be surprisingly rapid and profound, with lower reproductive activity observed only 10 days after mating pairs are moved to small indoor enclosures (Dickens and Bentley, 2014).

In a study that compared the vocal repertoire of captive and wild 'Alalā, Tanimoto et al. (2017) found that territorial broadcast calls recorded in the 1990s from a small wild population (i.e., from three of the last four breeding pairs) were absent from recordings of the captive repertoire. Yet, the captive birds routinely engage in matching loud caws and counter-cawing, which indicate a territorial function. In the wild, 'Alalā can regulate social and acoustic proximity. Thus, in our study, we suggest that close proximity at the breeding centers promotes visual and acoustic territorial signaling at an intensity that far exceeds that found in nature, with associated consequences mediated by HPA activation or behavioral disruption. Within the HEBCP, husbandry staff have often noted that members of 'Alalā pairs that had visual access to adult conspecifics seemed stressed by their neighbors, showing signs of stress-related behaviors, such as pace flying, hiding, or attempting to fight with neighbors through the wire mesh walls separating the compartments. In addition to possible physiological effects, observations suggest that conspecific proximity may interfere with important breeding and parental care behaviors. For instance, nesting dams who are stressed or distracted by neighboring conspecifics may leave their nests more frequently to defend their space, resulting in lower quality parental incubation, a known factor influencing 'Alalā hatchability (Hoeck et al., 2015). Agitated behavior may also increase the probability of damaging an egg. Since reproductive success provides a known animal welfare benefit, these anecdotal observations, and our study's quantitative findings, suggest that there may be negative welfare consequences associated with crowding, compromising important goals established by this and other conservation breeding programs (Greggor et al., 2018). Factors interfering with parental care are especially problematic as the program is undertaking a transition from reliance on puppet-rearing to parental-rearing that may produce higher quality birds for release in the nascent reintroduction program. For these reasons, husbandry staff began to address crowding issues by installing visual barriers in aviaries with more than two compartments, providing an unplanned experiment amenable to our analyses. Our 
findings corroborate and extend these concerns. While identifying the exact proximate mechanisms driving reduced reproductive output was beyond the scope of our retrospective analyses, our results pave the way for productive observational and experimental follow-on studies.

Our findings also shed light on the natural history of the species - little known before they went extinct in the wild - and inform reintroduction strategies. Although known to be territorial and to display aggression towards extra-pair conspecifics (Perkins, 1903; Banko, 2009), pre-decline population density of 'Alalā is unknown. Our findings suggest that reintroduction into small protected areas may have negative consequences if density is too high and pairs cannot establish nests away from other pairs. Indeed, although reintroductions to date have released immature 'Alalā that are more social and tolerant of conspecifics, as many of these individuals matured they began to exhibit intolerance towards nearby conspecifics, with possible cases of deadly aggression. Our findings also suggest the possibility of less obvious consequences, such as nesting failure, which may also result if pairs are too close. Future research should determine optimal social densities for nesting pairs to help guide release decisions.

Conservation breeding must become as efficient and effective as possible if it is to be retained as an important conservation tool that does not excessively drain resources that could be invested in other conservation endeavors. In an important critique, Snyder et al. (1996) identified a number of limitations that must be addressed to make captive breeding a viable, cost-effective solution. Among these limitations are the high costs and difficulties associated with establishing a sustainable captive population. The 'Alalā breeding program costs in excess of \$1 million annually, an expense borne by governmental partners (U.S. Fish \& Wildlife Service and the State of Hawai'i Division of Forestry and Wildlife), San Diego Zoo Global, as well as numerous foundations and private donors. As Hawaiian avifauna faces an unprecedented extinction crisis (Reed et al., 2012; Paxton et al. 2018), it is vital that we ensure breeding programs are as costefficient as possible, to avoid detrimental consequences for other recovery actions. To this end, it is critical to understand those husbandry factors that reduce productivity. By identifying and mitigating those factors, we can run a leaner, more efficient program, producing the number of birds required for reintroduction, while maintaining a smaller, more productive captive breeding population.

Despite the many challenges facing this conservation tool (Bowkett, 2009), recent years have seen the resurrection of conservation breeding among conservation practitioners (Bowkett, 2009; Conde et al., 2011). There are many reasons why practitioners are turning to captive propagation once again. Perhaps the most important reason is the continued deterioration of conditions for in situ conservation of many species now facing imminent extinction, but many improvements in husbandry science and efficiency of captive breeding have also begun to address key limitations identified by Snyder et al. (1996). Here, we have shown how retrospective analyses can inform husbandry and management in a critically endangered Hawaiian bird species, and provide a roadmap for gleaning lessons from similar legacy data available for other long-term conservation breeding programs. Until the recent reintroductions, the 'Alalā was extinct in the wild, thus representing an example of a species that can be recovered only through conservation breeding. Unfortunately, an increasing number of species find themselves in a similar predicament. Consequently, we advocate for the continued 
improvement and efficiency of conservation breeding programs through the application of scientific research - including forward-thinking hypothesis testing in an adaptive management framework (Canessa et al., 2016) and retrospective analyses to mine decades of experience with animal husbandry.

\section{References}

Banko, P.C., 2009. 'Alalā, in: Pratt T.K., Atkinson C.T., Banko P.C. , Jacobi J.D., Woodworth, B.L. (Ed.), Conservation Biology of Hawaiian Forest Birds: Implications for Island Avifauna. Yale University Press, New Haven, Connecticut, pp. 473-486.

Banko, P.C., Ball, D.L., Banko, W.E., 2002. Hawaiian crow Corvus hawaiiensus, in: Poole, A., Gill, F. (Eds.), The Birds of North America. Cornell Lab of Ornithology.

Barnosky, A.D., Matzke, N., Tomiya, S., Wogan, G.O.U., Swartz, B., Quental, T.B., Marshall, C., McGuire, J.L., Lindsey, E.L., Maguire, K.C., Mersey, B., Ferrer, E.A., 2011. Has the Earth's sixth mass extinction already arrived? Nature 471, 51.

Barton, K., 2018. MuMIn: Multi-Model Inference. R package version 1.42.1. https://CRAN.Rproject.org/package=MuMIn.

Belsley, D., Kuh, E., Welsch, R., 1980. Regression diagnostics: identifying influential data and sources of collinearity. Wiley, New York.

Bowkett, A.E., 2009. Recent Captive-Breeding Proposals and the Return of the Ark Concept to Global Species Conservation. Conserv. Biol. 23, 773-776. https://doi.org/10.1111/j.15231739.2008.01157.x

Brakes, P., Dall, S.R.X., Aplin, L.M., Bearhop, S., Carroll, E.L., Ciucci, P., Fishlock, V., Ford, J.K.B., Garland, E.C., Keith, S.A., McGregor, P.K., Mesnick, S.L., Noad, M.J., di Sciara, G.N., Robbins, M.M., Simmonds, M.P., Spina, F., Thornton, A., Wade, P.R., Whiting, M.J., Williams, J., Rendell, L., Whitehead, H., Whiten, A., Rutz, C., 2019. Animal cultures matter for conservation. Science (80-.). 363, 1032-1034.

https://doi.org/10.1126/science.aaw3557

Canessa, S., Guillera-Arroita, G., Lahoz-Monfort, J.J., Southwell, D.M., Armstrong, D.P., Chadès, I., Lacy, R.C., Converse, S.J., 2016. Adaptive management for improving species conservation across the captive-wild spectrum. Biol. Conserv. 199, 123-131. https://doi.org/10.1016/j.biocon.2016.04.026

Carlstead, K., 1996. Effects of Captivity on the Behavior of Wild Animals, in: Kleiman, D.G., Allen, M.E., Thompson, K.V., Lumpkin, S. (Ed.), Wild Mammals in Captivity. University of Chicago Press, Chicago, pp. 317-333.

Christensen, R.H.B., 2018. ordinal - Regression Models for Ordinal Data. R package version 2018.4-19. http://www.cran.r-project.org/package=ordinal/.

Conde, D.A., Flesness, N., Colchero, F., Jones, O.R., Scheuerlein, A., 2011. An Emerging Role of Zoos to Conserve Biodiversity. Science (80-. ). 331, 1390-1391. 
https://doi.org/10.1126/science.1200674

Creel, S., Dantzer, B., Goymann, W., Rubenstein, D.R., 2013. The ecology of stress: effects of the social environment. Funct. Ecol. 27, 66-80. https://doi.org/10.1111/j.13652435.2012.02029.x

Culliney, S., Pejchar, L., Switzer, R., Ruiz-Gutierrez, V., 2012. Seed dispersal by a captive corvid : the role of the 'Alalā (Corvus hawaiiensis) in shaping Hawai'i's plant communities 22, 1718-1732. https://doi.org/10.2307/41722888

Dickens, M.J., Bentley, G.E., 2014. Hormones and behavior stress, captivity, and reproduction in a wild bird species. Horm. Behav. 66, 685-693. https://doi.org/10.1016/j.yhbeh.2014.09.011

Fox, J., Weisberg, S., 2011. An R companion to Applied Regression, Second. ed. Sage, Thousand Oaks, CA.

Gascon, C., Brooks, T.M., Contreras-MacBeath, T., Heard, N., Konstant, W., Lamoreux, J., Launay, F., Maunder, M., Mittermeier, R.A., Molur, S., Al Mubarak, R.K., Parr, M.J., Rhodin, A.G.J., Rylands, A.B., Soorae, P., Sanderson, J.G., Vié, J.-C., 2015. The Importance and Benefits of Species. Curr. Biol. 25, R431-R438. https://doi.org/10.1016/j.cub.2015.03.041

Gelman, A., Su, Y.S., 2018. arm: Data Analysis Using Regression and Multilevel/Hierarchical Models. R package version 1.10-1. https://CRAN.R-project.org/package=arm.

Greggor, A.L., Vicino, G.A., Swaisgood, R.R., Fidgett, A.L., Brenner, D., Kinney, M.E., Farabaugh, S.M., Masuda, B.M., Lamberski, N., 2018. Animal welfare in conservation breeding: applications and challenges. Front. Vet. Sci. 5, 1-6.

Grueber, C.E., Nakagawa, S., Laws, R.J., Jamieson, I.G., 2011. Multimodel inference in ecology and evolution: Challenges and solutions. J. Evol. Biol. 24, 699-711. https://doi.org/10.1111/j.1420-9101.2010.02210.x

Hearn, G.W., Berghaier, R.W., George, D.D., 1996. Evidence for social enhancement of reproduction in two Eulemur species. Zoo Biol. 15, 1-12. https://doi.org/10.1002/(SICI)1098-2361(1996)15:1<1::AID-ZOO1>3.0.CO;2-F

Hoeck, P.E.A., Wolak, M.E., Switzer, R.A., Kuehler, C.M., Lieberman, A.A., 2015. Effects of inbreeding and parental incubation on captive breeding success in Hawaiian crows. Biol. Conserv. 184, 357-364. https://doi.org/10.1016/j.biocon.2015.02.011

Hooper, D.U., Adair, E.C., Cardinale, B.J., Byrnes, J.E.K., Hungate, B.A., Matulich, K.L., Gonzalez, A., Duffy, J.E., Gamfeldt, L., O'Connor, M.I., 2012. A global synthesis reveals biodiversity loss as a major driver of ecosystem change. Nature 486, 105-108.

https://doi.org/10.1038/nature11118

James, H.F., Olson, S.L., 1991. Descriptions of thirty-two new species of birds from the 
Hawaiian Islands: Part II. Passeriformes. Ornithol. Monogr. 1-88.

https://doi.org/doi:10.2307/40166794

Klump, B.C., Masuda, B.M., St Clair, J.J.H., Rutz, C., 2018. Preliminary observations of toolprocessing behaviour in Hawaiian crows Corvus hawaiiensis. Commun. Integr. Biol. 11, e1509637. https://doi.org/10.1080/19420889.2018.1509637

Li, D., Wintle, N.J.P., Zhang, G., Wang, C., Luo, B., Martin-Wintle, M.S., Owen, M.A., Swaisgood, R.R., 2017. Analyzing the past to understand the future: Natural mating yields better reproductive rates than artificial insemination in the giant panda. Biol. Conserv. 216, 10-17. https://doi.org/10.1016/j.biocon.2017.09.025

Lindburg, D.G., Fitch-Snyder, H., 1994. Use of behavior to evaluate reproductive problems in captive mammals. Zoo Biol. 13, 433-445. https://doi.org/10.1002/zoo.1430130506

Morgan, K.N., Tromborg, C.T., 2007. Sources of stress in captivity. Appl. Anim. Behav. Sci. 102, 262-302. https://doi.org/10.1016/j.applanim.2006.05.032

Paxton, E.H., Laut, M., Vetter, J.P., Kendall, S.J., 2018. Research and management priorities for Hawaiian forest birds. Condor 120, 557-565. https://doi.org/10.1650/CONDOR-18-25.1

Perkins, R., 1903. Vertebrata. in Fauna Hawaiiensis vol. 1, pt. 4 (D.Sharpe, ed.). Univ. Press, Cambridge, U.K.

R Core Team, 2017. R: A language and environment for statistical computing. R Foundation for Statistical Computing, Vienna, Austria. URL https://www.R-project.org/.

Reed, J.M., DesRochers, D.W., VanderWerf, E.A., Scott, J.M., 2012. Long-Term Persistence of Hawaii's Endangered Avifauna through Conservation-Reliant Management. Bioscience 62, 881-892. https://doi.org/10.1525/bio.2012.62.10.8

Richardson, L., Loomis, J., 2009. The total economic value of threatened, endangered and rare species: An updated meta-analysis. Ecol. Econ. 68, 1535-1548.

https://doi.org/10.1016/j.ecolecon.2008.10.016

Rutz, C., Klump, B.C., Komarczyk, L., Leighton, R., Kramer, J., Wischnewski, S., Sugasawa, S., Morrissey, M.B., James, R., St Clair, J.J.H., Switzer, R.A., Masuda, B.M., 2016. Discovery of species-wide tool use in the Hawaiian crow. Nature 537, 403-407.

https://doi.org/10.1038/nature19103

Snyder, Noel, Toone, W.D., Miller, B., 1996. Limitations of captive breeding in endangered species recovery. Conserv. Biol. 102, 71-77. https://doi.org/10.1111/j.15231739.2008.01163.x

Stephens, P.A., Sutherland, W.J., 1999. Consequences of the Allee effect for behaviour, ecology and conservation. Trends Ecol. Evol. 14, 401-405. https://doi.org/10.1016/S01695347(99)01684-5 
Swaisgood, R.R., Schulte, B.A., 2010. Applying knowledge of mammalian social organization, mating systems and communication to management, in: Kleiman, D.G., Thompson, K.B., Baer, C.K. (Ed.), Wild Mammals in Captivity. University of Chicago Press, Chicago.

Tanimoto, A.M., Hart, P.J., Pack, A.A., Switzer, R., Banko, P.C., Ball, D.L., SebastiánGonzález, E., Komarczyk, L., Warrington, M.H., 2017. Changes in vocal repertoire of the Hawaiian crow, Corvus hawaiiensis, from past wild to current captive populations. Anim. Behav. 123, 427-432. https://doi.org/10.1016/j.anbehav.2016.11.017

Weiser, E.L., Grueber, C.E., Kennedy, E.S., Jamieson, I.G., 2015. Unexpected positive and negative effects of continuing inbreeding in one of the world's most inbred wild animals. Evolution (N. Y). 70, 154-166. https://doi.org/10.1111/evo.12840 


\section{Tables}

Table 1. Results from model averaging: estimated parameter coefficients ( $\beta$ ), standard errors (SE), 95\% confidence intervals (CI), and relative importance scores (RI) for each fixed effect. Fixed effects with the two highest RI scores are highlighted in grey. The six submodels used in model averaging are provided in the Supplementary Material. The variance inflation factors (VIF) for each fixed effect are reported. Random effects included in the GLMM used in model averaging were the identities of the male and female comprising each breeding pair $(\mathrm{n}=141$ pairs) and year $(n=19$ years/breeding seasons $)$.

\begin{tabular}{lccccc}
\hline Fixed effects & VIF & $\beta$ & SE & CI & RI \\
\hline \hline Intercept & ---- & -0.19 & 0.28 & $(-0.74,0.36)$ & ---- \\
Distance $(\mathrm{m})$ & 2.23 & 1.78 & 0.55 & $(0.70,2.86)$ & 1.00 \\
Visual access & 1.66 & -0.75 & 0.43 & $(-1.59,0.08)$ & 0.73 \\
Social density $(10 \mathrm{~m})$ & 1.83 & 0.75 & 0.47 & $(-0.17,1.67)$ & 0.64 \\
Location & 2.07 & 0.42 & 0.76 & $(-1.07,1.92)$ & 0.12 \\
Single 9 neighbor & 1.24 & -0.31 & 0.84 & $(-1.96,1.33)$ & 0.11 \\
\hline
\end{tabular}


Figures

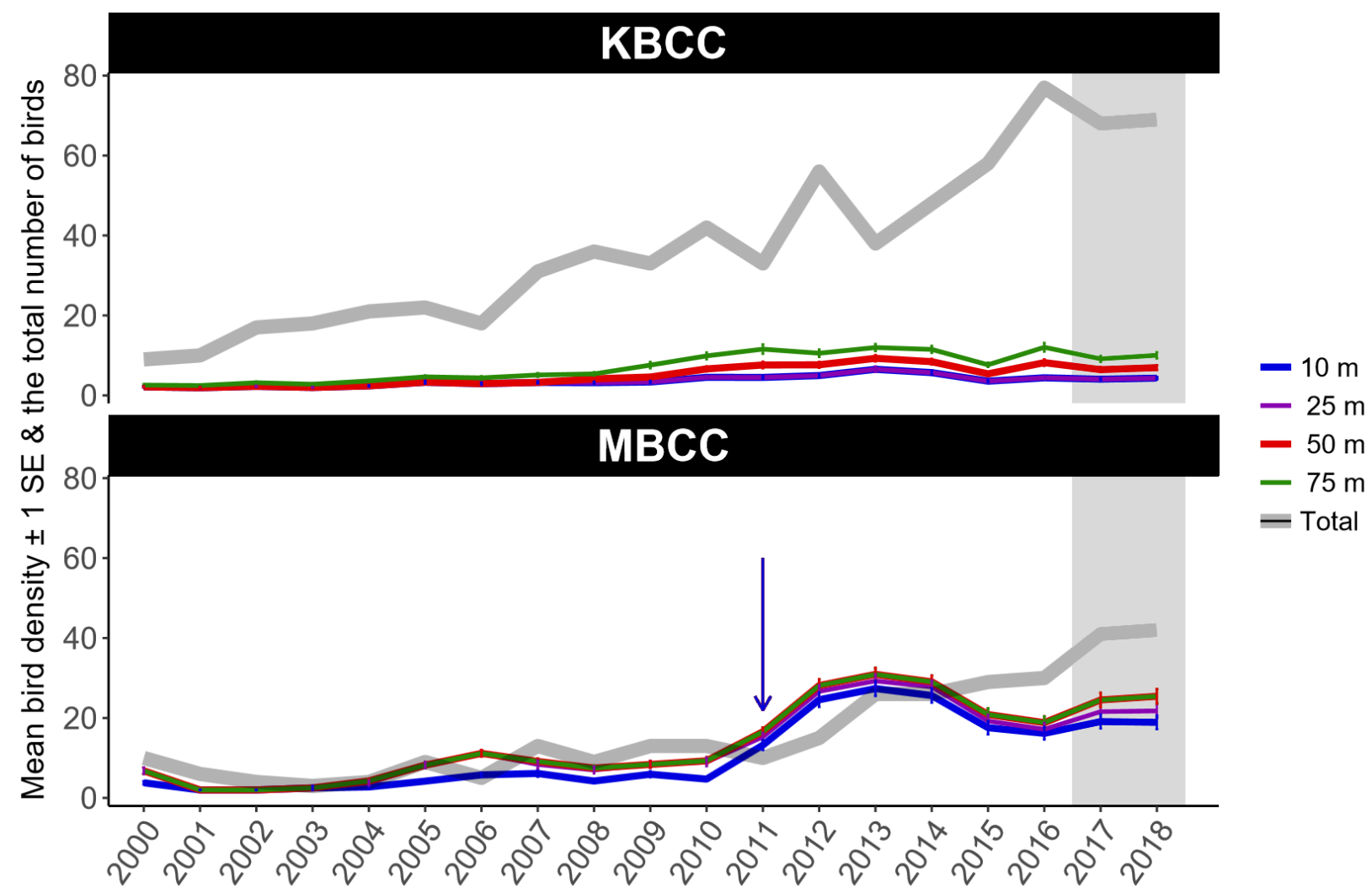

Figure 1. Breeding center (KBCC and MBCC) timelines illustrating the social density of 'Alalā within $10,25,50$, and $75 \mathrm{~m}$ and the total number of birds located at each breeding center per year. The arrow in the MBCC timeline highlights 2011, the first year in which newly constructed aviaries (all within $10 \mathrm{~m}$ of one another and each with 6 compartments) housed 'Alalā,

explaining the increase in social density at MBCC. The shaded areas in 2017 and 2018 highlight years in which birds were successfully released into the Pu'u Maka'ala Natural Area Reserve on the island of Hawai' $i$. A total of 21 birds were released in these years, 11 in 2017 and 10 in 2018, but the density of birds at both breeding centers remained similar to earlier years. 


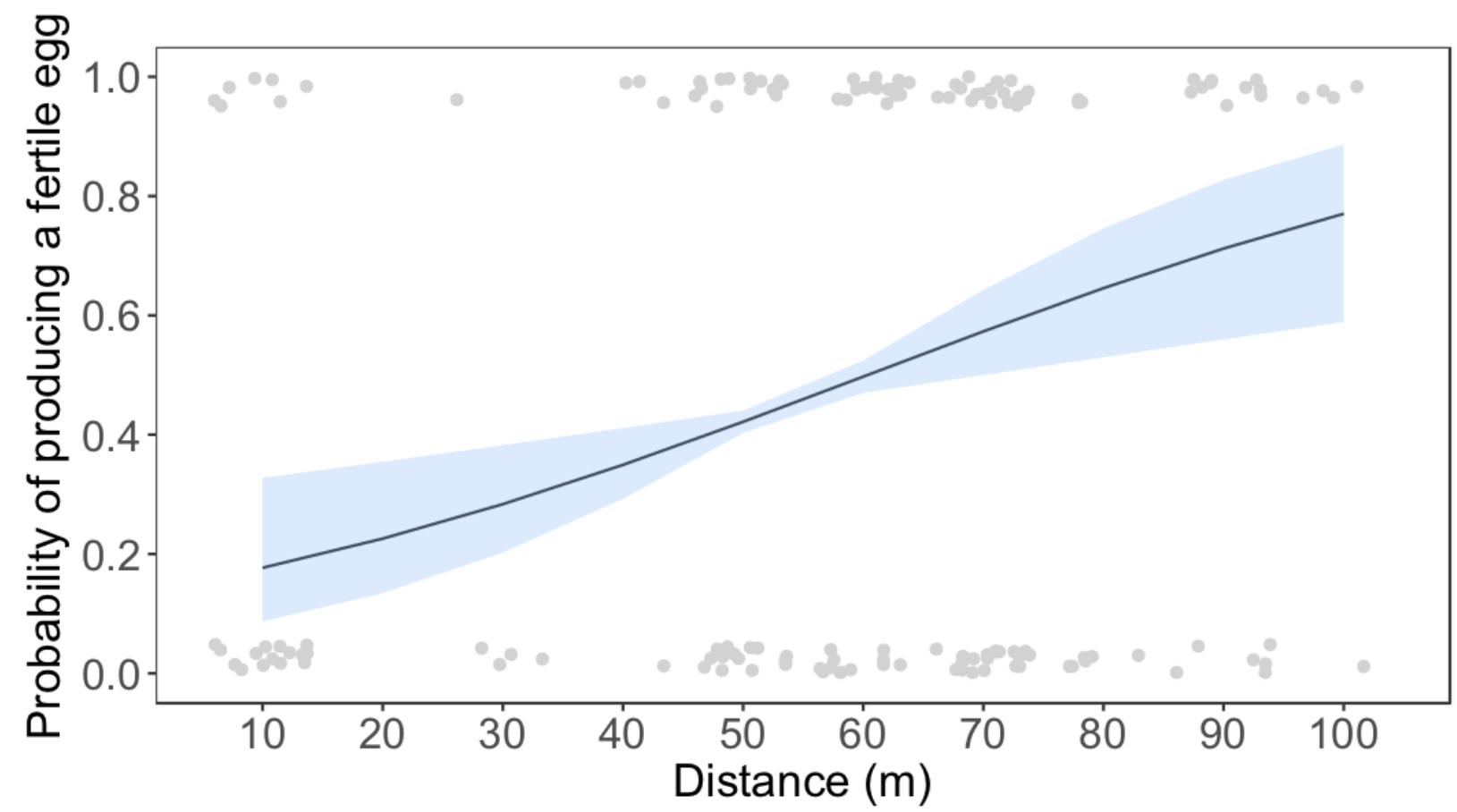

Figure 2. The relationship between inter-aviary distance and the probability of an 'Alalā breeding pair producing a fertile egg. Predictions were calculated based on the current range of distances between the aviaries across the two breeding centers ( $\sim 4$ to $100 \mathrm{~m})$. The $95 \%$ confidence intervals were calculated using parametric bootstrapping from a normal distribution with a mean equal to the model averaged coefficient of distance and its unconditional standard error, both of which are outputs of model averaging in the MuMIn package. Predictions in this figure were back-transformed using the invlogit function from the arm package (Gelman and Su, 2018) for ease of interpretation. Points are the observed values of reproductive success and are offset slightly in this figure for readability. The total number of successful vs. unsuccessful pairs per distance class per year is provided in the Supplementary Material (Table S8). 

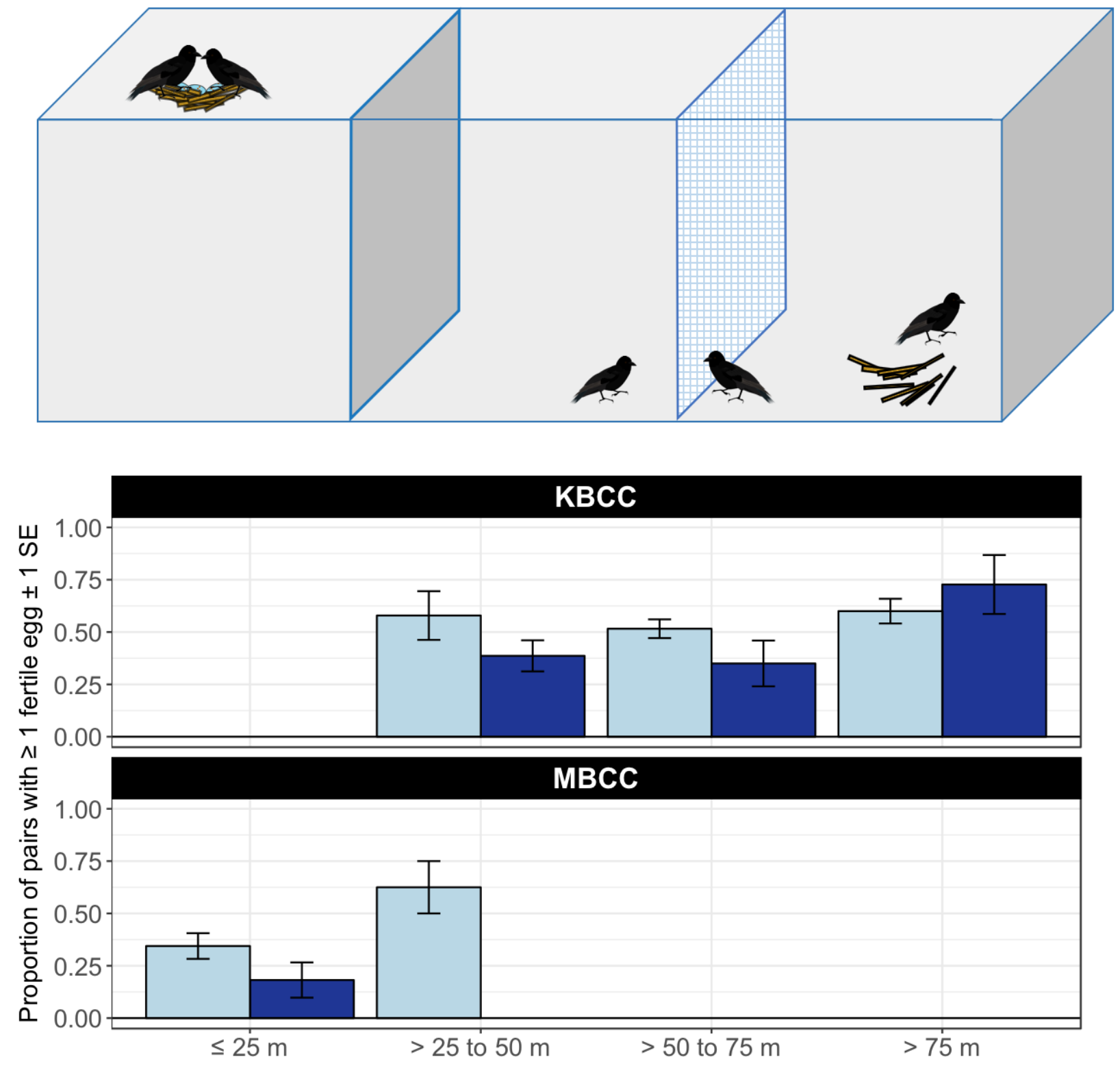

$\square$ No visual access $\square$ Visual access

Figure 3. (Top) Schematic of a three-compartment aviary that contains two breeding pairs, one with visual access (right) to a single adult neighbor (center) through a wire mesh wall and the other without visual access (left) to the same single neighbor due to the presence of a visual barrier. In this scenario, the pair with visual access to the single bird did not engage in breeding behaviors (e.g., nest building) nor did they produce a fertile egg. The pair without visual access built a nest and produced one or more fertile eggs. The 'Alalā graphic used in this schematic is freely available from: Hawkey, Jane, Integration and Application Network, University of Maryland Center for Environmental Science (ian.umces.edu/imagelibrary/). (Bottom) The proportion of "Alalā breeding pairs that produced $\geq 1$ fertile egg within each inter-aviary distance class with or without visual access to adult conspecifics. The current maximum distance between 
the aviaries at $\mathrm{MBCC}$ is $\sim 50 \mathrm{~m}$ whereas the current minimum distance between the aviaries at $\mathrm{KBCC}$ is $\sim 30 \mathrm{~m}$. Note that not all of the distance classes included data for breeding pairs with and without visual access to adult conspecifics for comparison (e.g., the $>25$ to $50 \mathrm{~m}$ distance category at MBCC had no data from breeding pairs with visual access). 


\section{Supplementary Material}

Table S1. The total number of aviaries and compartments, mean inter-aviary distances, and the total number of aviaries within each distance class (Up to $25 \mathrm{~m}, 25$ to $50 \mathrm{~m}, 50$ to $75 \mathrm{~m}$, and More than $75 \mathrm{~m}$ ) at each breeding center as of December 2018. Aviary dimensions range from $\sim 74$ to $149 \mathrm{~m}^{2}$, and individual compartments are $\sim 22$ to $37 \mathrm{~m}^{2}$.

\begin{tabular}{lllcccc}
\hline $\begin{array}{l}\text { Breeding } \\
\text { center }\end{array}$ & $\begin{array}{l}\text { Total aviaries (total } \\
\text { compartments) }\end{array}$ & $\begin{array}{l}\text { Mean inter-aviary } \\
\text { distance }(\mathrm{m}) \pm \mathrm{SE}\end{array}$ & Up to $25 \mathrm{~m}$ & 25 to $50 \mathrm{~m}$ & 50 to $75 \mathrm{~m}$ & More than $75 \mathrm{~m}$ \\
\hline KBCC & $26(63)$ & $62.1 \pm 3.8$ & 0 & 8 & 13 & 5 \\
MBCC & $9(34)$ & $19.2 \pm 6.1$ & 6 & 3 & 0 & 0 \\
\hline
\end{tabular}

Table S2. Pearson correlation coefficients between numeric fixed effects. All categorical variables were dummy coded so that they could be standardized using the rescale function from the arm package (Gelman \& Su, 2018) in the global GLMM used in model averaging.

\begin{tabular}{|c|c|c|c|c|c|c|c|c|c|c|c|c|c|}
\hline Variable & loc & bdistm & visual & male & female & mult & nfemales & nmales & ntotal & $\mathrm{d} 75$ & $\mathrm{~d} 50$ & $\mathrm{~d} 25$ & $\mathrm{~d} 10$ \\
\hline Location (loc) & 1.00 & 0.79 & 0.02 & -0.03 & 0.04 & -0.43 & -0.38 & -0.39 & -0.43 & -0.47 & -0.59 & -0.65 & -0.54 \\
\hline Inter-aviary distance (bdistm) & 0.79 & 1.00 & -0.20 & -0.09 & 0.03 & -0.56 & -0.49 & -0.54 & -0.57 & -0.65 & -0.68 & -0.67 & -0.58 \\
\hline Visual access (visual) & 0.02 & -0.20 & 1.00 & 0.30 & 0.29 & 0.56 & 0.54 & 0.63 & 0.65 & 0.53 & 0.43 & 0.33 & 0.39 \\
\hline Single $\precsim$ neighbor (male) & -0.03 & -0.09 & 0.30 & 1.00 & -0.04 & -0.14 & -0.12 & 0.07 & -0.01 & 0.10 & 0.06 & -0.01 & -0.01 \\
\hline Single +neighbor (female) & 0.04 & 0.03 & 0.29 & -0.04 & 1.00 & -0.12 & 0.15 & -0.10 & -0.01 & -0.05 & -0.06 & -0.05 & -0.05 \\
\hline Multiple neighbors (mult) & -0.43 & -0.56 & 0.56 & -0.14 & -0.12 & 1.00 & 0.77 & 0.81 & 0.87 & 0.61 & 0.58 & 0.58 & 0.56 \\
\hline $\mathrm{N}$ females in aviary (nfemales) & -0.38 & -0.49 & 0.54 & -0.12 & 0.15 & 0.77 & 1.00 & 0.65 & 0.86 & 0.59 & 0.58 & 0.61 & 0.62 \\
\hline $\mathrm{N}$ males in aviary (nmales) & -0.39 & -0.54 & 0.63 & 0.07 & -0.10 & 0.81 & 0.65 & 1.00 & 0.95 & 0.75 & 0.73 & 0.72 & 0.74 \\
\hline $\mathrm{N}$ birds in aviary (ntotal) & -0.43 & -0.57 & 0.65 & -0.01 & -0.01 & 0.87 & 0.86 & 0.95 & 1.00 & 0.75 & 0.73 & 0.74 & 0.76 \\
\hline Density of birds within $\sim 75 \mathrm{~m}(\mathrm{~d} 75)$ & -0.47 & -0.65 & 0.53 & 0.10 & -0.05 & 0.61 & 0.59 & 0.75 & 0.75 & 1.00 & 0.96 & 0.87 & 0.84 \\
\hline Density of birds within $\sim 50 \mathrm{~m}(\mathrm{~d} 50)$ & -0.59 & -0.68 & 0.43 & 0.06 & -0.06 & 0.58 & 0.58 & 0.73 & 0.73 & 0.96 & 1.00 & 0.93 & 0.89 \\
\hline Density of birds within $\sim 25 \mathrm{~m} \mathrm{(d25)}$ & -0.65 & -0.67 & 0.33 & -0.01 & -0.05 & 0.58 & 0.61 & 0.72 & 0.74 & 0.87 & 0.93 & 1.00 & 0.97 \\
\hline Density of birds within $\sim 10 \mathrm{~m} \mathrm{(d10)}$ & -0.54 & -0.58 & 0.39 & -0.01 & -0.05 & 0.56 & 0.62 & 0.74 & 0.76 & 0.84 & 0.89 & 0.97 & 1.00 \\
\hline
\end{tabular}

Table S3. Summary of the top GLMM submodel set used in model averaging. These models were derived from the dataset that excluded subadults (birds $\leq 2$ years of age). The degrees of freedom $(d f), \mathrm{AIC}_{\mathrm{C}}$ scores $\left(\mathrm{AIC}_{\mathrm{C}}\right)$, differences between the $\mathrm{AIC}_{\mathrm{C}}$ score of each model and the best model $\left(\triangle \mathrm{AIC} \mathrm{C}_{\mathrm{C}}\right)$, and Akaike weights ( $\mathrm{AIC} \mathrm{C}_{\mathrm{C}}$ weight) are reported. All models included the identities of the male and female comprising each breeding pair ( $\mathrm{n}=141$ pairs) and year $(\mathrm{n}=19$ years/breeding seasons) as random effects. Model averaging results are reported in Table 1.

\begin{tabular}{lcccc}
\hline Model & $d f$ & $\mathrm{AIC}_{\mathrm{C}}$ & $\Delta \mathrm{AIC}_{\mathrm{C}}$ & AIC $_{\mathrm{C}}$ weight \\
\hline \hline$\beta_{0}+$ distance + visual access + social density $(10 \mathrm{~m})$ & 7 & 478.84 & 0.00 & 0.29 \\
$\beta_{0}+$ distance + visual access & 6 & 479.54 & 0.70 & 0.21 \\
$\beta_{0}+$ distance & 5 & 480.17 & 1.33 & 0.15 \\
$\beta_{0}+$ distance + visual access + social density $(10 \mathrm{~m})+$ location & 8 & 480.61 & 1.77 & 0.12 \\
$\beta_{0}+$ distance + social density $(10 \mathrm{~m})$ & 6 & 480.64 & 1.80 & 0.12 \\
$\beta_{0}+$ distance + visual access + social density $(10 \mathrm{~m})+$ single + neighbor & 8 & 480.78 & 1.94 & 0.11 \\
\hline
\end{tabular}

Table S4. Model averaging results from the analysis of a restricted dataset that only included breeding pairs that resided in the same aviary for 1 to 3 consecutive years (i.e., data for pairs in the same aviary for 4 to 8 years were excluded from the dataset prior to this analysis): estimated parameter coefficients $(\beta)$, standard errors (SE), $95 \%$ confidence intervals $(\mathrm{CI})$, and relative 
importance scores (RI) for each fixed effect. Fixed effects with the two highest RI scores are highlighted in grey. The four models used in model averaging are provided in Table S4. The variance inflation factors (VIF) for each fixed effect are reported. Random effects included in the GLMM used in model averaging were the identities of the male and female comprising each breeding pair $(\mathrm{n}=141$ pairs $)$ and year $(\mathrm{n}=19$ years/breeding seasons).

\begin{tabular}{lccccc}
\hline Fixed effects & VIF & $\beta$ & SE & CI & RI \\
\hline \hline Intercept & ---- & -0.19 & 0.32 & $(-0.81,0.43)$ & ---- \\
Distance $(\mathrm{m})$ & 2.11 & 1.99 & 0.63 & $(0.74,3.23)$ & 1.00 \\
Visual access & 1.61 & -1.11 & 0.49 & $(-2.07,-0.15)$ & 1.00 \\
Social density $(10 \mathrm{~m})$ & 1.76 & 0.85 & 0.53 & $(-0.20,1.89)$ & 0.69 \\
Location & 2.00 & 0.49 & 0.84 & $(-1.15,2.13)$ & 0.16 \\
Single + neighbor & -0.40 & -0.31 & 0.94 & $(-2.25,1.44)$ & 0.15 \\
\hline
\end{tabular}

Table S5. Summary of the top GLMM submodel set used in model averaging. This model set was derived from the restricted dataset that only included breeding pairs that resided in the same aviary for 1 to 3 consecutive years (i.e., data for pairs in the same aviary for 4 to 8 years were excluded from the dataset prior to this analysis). The degrees of freedom ( $d f), \mathrm{AIC}_{\mathrm{C}}$ scores $\left(\mathrm{AIC}_{\mathrm{C}}\right)$, differences between $\mathrm{AIC}_{\mathrm{C}}$ of each model and the based model $\left(\triangle \mathrm{AIC} \mathrm{C}_{\mathrm{C}}\right)$, and Akaike weights $\left(\mathrm{AIC}_{\mathrm{C}}\right.$ weight) are reported. All models included the identities of the male and female comprising each breeding pair $(\mathrm{n}=141$ pairs $)$ and year $(\mathrm{n}=19$ years/breeding seasons $)$ as random effects. Model averaging results are reported in Table S3.

\begin{tabular}{lcccc}
\hline Model & $d f$ & $\mathrm{AIC}_{\mathrm{C}}$ & $\Delta \mathrm{AIC}_{\mathrm{C}}$ & $\mathrm{AIC}_{\mathrm{C}}$ weight \\
\hline \hline$\beta_{0}+$ distance + visual access + social density $(10 \mathrm{~m})$ & 7 & 402.87 & 0.00 & 0.38 \\
$\beta_{0}+$ distance + visual access & 6 & 403.30 & 0.43 & 0.31 \\
$\beta_{0}+$ distance + visual access + social density $(10 \mathrm{~m})+$ location & 8 & 404.61 & 1.74 & 0.16 \\
$\beta_{0}+$ distance + visual access + social density $(10 \mathrm{~m})+$ single + neighbor & 8 & 404.77 & 1.91 & 0.15 \\
\hline
\end{tabular}

Table S6. Model averaging results from the dataset that included subadults (birds $\leq 2$ years of age): estimated parameter coefficients $(\beta)$, standard errors (SE), $95 \%$ confidence intervals (CI), and relative importance scores (RI) for each fixed effect. Fixed effects with the two highest RI scores are highlighted in grey. The three models used in model averaging are provided in Table S6. The variance inflation factors (VIF) for each fixed effect are reported. Random effects included in the GLMM used in model averaging were the identities of the male and female comprising each breeding pair $(\mathrm{n}=142$ pairs $)$ and year $(\mathrm{n}=19$ years/breeding seasons $)$.

\begin{tabular}{lccccc}
\hline Fixed effects & VIF & $\beta$ & SE & CI & RI \\
\hline \hline Intercept & --- & -0.19 & 0.29 & $(-0.76,0.37)$ & ---- \\
Distance $(\mathrm{m})$ & 2.15 & 1.43 & 0.52 & $(0.42,2.45)$ & 1.00 \\
Visual access & 1.60 & -0.89 & 0.41 & $(-1.70,-0.08)$ & 1.00 \\
Social density $(10 \mathrm{~m})$ & 1.80 & 0.46 & 0.47 & $(-0.46,1.37)$ & 0.29 \\
Location & 2.12 & 0.23 & 0.75 & $(-1.25,1.70)$ & 0.19 \\
\hline
\end{tabular}


Table S7. Summary of the top GLMM submodel set used in model averaging. This model set was derived from the dataset that included subadults (birds $\leq 2$ years of age). The degrees of freedom $(d f), \mathrm{AIC}_{\mathrm{C}}$ scores $\left(\mathrm{AIC}_{\mathrm{C}}\right)$, differences between $\mathrm{AIC}_{\mathrm{C}}$ of each model and the based model $\left(\triangle \mathrm{AIC}_{\mathrm{C}}\right)$, and Akaike weights (AIC $\mathrm{C}$ weight) are reported. All models included the identities of the male and female comprising each breeding pair $(n=142$ pairs $)$ and year $(n=19$ years/breeding seasons) as random effects. Model averaging results are reported in Table S5.

\begin{tabular}{lcccc}
\hline Model & $d f$ & $\mathrm{AIC}_{\mathrm{C}}$ & $\Delta \mathrm{AIC}_{\mathrm{C}}$ & $\mathrm{AIC}_{\mathrm{C}}$ weight \\
\hline \hline$\beta_{0}+$ distance + visual access & 6 & 482.02 & 0.00 & 0.52 \\
$\beta_{0}+$ distance + visual access + social density $(10 \mathrm{~m})$ & 7 & 483.16 & 1.14 & 0.29 \\
$\beta_{0}+$ distance + visual access + location & 7 & 484.00 & 1.98 & 0.19 \\
\hline
\end{tabular}

Table S8. The total number of reproductively successful vs. unsuccessful 'Alalā pairs per distance class (Up to $25 \mathrm{~m}, 25$ to $50 \mathrm{~m}, 50$ to $75 \mathrm{~m}$, and More than $75 \mathrm{~m}$ ) in each year across both breeding centers (\# successful, \# unsuccessful; nd = no data).

\begin{tabular}{ccccc}
\hline Year & Up to $25 \mathrm{~m}$ & 25 to $50 \mathrm{~m}$ & 50 to $75 \mathrm{~m}$ & More than $75 \mathrm{~m}$ \\
\hline 2000 & 2,0 & nd, 1 & 1,3 & nd, 1 \\
2001 & 1,0 & nd, 1 & 2,2 & 2,0 \\
2002 & nd, 1 & 0,0 & 2,2 & 1,2 \\
2003 & nd, 1 & 0,0 & 2,2 & 3,1 \\
2004 & nd, 1 & 0,0 & 5,2 & 2,2 \\
2005 & nd, 2 & 0,0 & 1,5 & 4,1 \\
2006 & nd, 1 & 0,0 & 2,2 & 3,1 \\
2007 & nd, 2 & 1,0 & 3,4 & 2,2 \\
2008 & 0,0 & nd, 2 & 3,4 & 2,2 \\
2009 & 1,1 & nd, 1 & 2,6 & 4,1 \\
2010 & 1,3 & 1,2 & 3,4 & 3,2 \\
2011 & 2,3 & 1,0 & 3,4 & 2,3 \\
2012 & 1,5 & 2,2 & 5,3 & 4,1 \\
2013 & nd, 7 & 4,0 & 4,4 & 2,2 \\
2014 & 5,5 & 4,3 & 4,4 & 2,2 \\
2015 & 2,5 & 4,6 & 4,9 & 3,2 \\
2016 & 3,3 & 6,10 & 8,6 & 4,2 \\
2017 & 4,8 & 8,7 & 10,2 & 6,1 \\
2018 & 3,10 & 7,8 & 8,6 & 1,3 \\
\hline
\end{tabular}

